\title{
Boundary value problems for nonlinear systems with generalized second-order differences
}

\section{RODICA LUCA}

\section{ABSTRACT.}

In a real Hilbert space, we investigate the existence and uniqueness of the solutions for two classes of infinite nonlinear systems with generalized second-order differences, one of them subject to a boundary condition. Some applications to nonlinear differential systems with monotone operators are also presented.

\section{REFERENCES}

[1] Aftabizadeh, A. R. and Pavel, N. H., Nonlinear boundary value problems for some ordinary and partial differential equations associated with monotone operators, J. Math. Anal. Appl. 156 (1991), 535-557

[2] Agarwal, R. P. and Wong, P. J. Y., Advanced Topics in Difference Equations, Mathematics and Its applications 404, Kluwer Academic, Dordrecht, 1997

[3] Attouch, H., On the maximality of the sum of two maximal monotone operators, Nonlinear Anal., Theory Methods Appl. 5 (1981), 143-147

[4] Barbu, V., Nonlinear Semigroups and Differential Equations in Banach Spaces, Noordhoff, Leyden, 1976

[5] Brezis, H., Operateurs Maximaux Monotones et Semigroupes de Contractions dans les Espaces de Hilbert, North-Holland, Amsterdam, 1973

[6] Ladde, S., Lakshmikantham, V. and Vatsalo, A. S., Monotone, Iterative Techniques for Nonlinear Differential Equations, Monographs, Advanced Texts and Surveys in Pure and Applied Mathematics, 27 Pitman, 1985

[7] Luca, R., Existence and uniqueness for a nonlinear discrete hyperbolic system, Nonlinear Anal., Theory Methods Appl. 67 (2007), 2433-2446

[8] Luca, R., Existence and asymptotic behaviour for a discrete hyperbolic system, J. Math. Anal. Appl. 329 (2007), 191-205

[9] Luca, R., On a nonlinear discrete hyperbolic system, Asymptotic Anal. 51 (2007), No. 3-4, 289-302

[10] Luca, R., On a nonlinear differential problem with second-order differences, Anal. Stiint. Univ. Al. I. Cuza Iasi LIV (2008), f.2, 261-277

[11] Luca, R., Differential systems with second-order differences in Hilbert spaces, PanAmer. Math. J. 18 (2008), No. 3, 59-67

[12] Luca, R., Nonlinear differential problems with first- or second-order differences in Hilbert spaces, Nonlinear Anal., Theory Methods Appl. 71 (2009), e81-e97

GH. ASACHI TECHNICAL UNIVERSITY

DEPARTMENT OF MATHEMATICS

CAROL I 11, 700506, IASI, ROMANIA

E-mail address: rluca@math.tuiasi.ro 